\title{
ПРАВОВЫЕ ПРОБЛЕМЫ ПЛАТЫ ЗА УСЛУГИ, НЕОБХОДИМЫЕ И ОБЯЗАТЕЛЬНЫЕ ДЛЯ ПРЕДОСТАВЛЕНИЯ УСЛУГ ОРГАНАМИ ПУБЛИЧНОЙ ВЛАСТИ
}

Аннотация. В статье рассматриваются проблемы, возникающие с платой за публичные услуги. Автор отмечает, что на данный момент Правительством взят курс на упорядочение взимания платы при предоставлении публичных услуг, предполагающий отмену такой платы или ее перевод в государственную пошлину. Требуя нормативного закрепления исчерпывающих перечней необходимых и обязательных услуг, законодатель прямо не ограничивает возможности оказания их на платной основе. Но как отмечает автор, не исключено оказание таких услуг на бесплатной для заявителя основе. На протяжении всей статьи автор рассматривает моменты платности и бесплатности необходимых и обязательных публичных услуг, анализируя российское законодательство. По итогам данной статьи автором предлагаются различные варианты для разрешения данной проблемы, например усиление публичноправовой составляющей регулирования, в рамках которого могли бы быть определены правовые основы организации предоставления необходимых и обязательных услуг и формирования платы за такие услуги.

Ключевые слова: государственные услуги, платность услуг, бесплатность услуг, обязательныле услуги, необходимые услуги, принципь формирования платы, государственные органы, коммерииализация публичной власти, субсидиарная ответственность, исполнительно-распорядительные полномочия.

Review. The article concerns the problems concerning payment for public services. The author notes that currently the Government aims to organize the payments for public services, providing for cancelling such payments or their transfer into the official fees. Requiring the normative provisions for the limited lists of obligatory and necessary services, the legislator does not directly exclude payment for such service, nor is excluded free of charge provision of such services. Throughout the article the author evaluates the issues of charges for such obligatory public services, analyzing the Russian legislation. As a result of the article, the author provides various options for resolving such a problem, such as strengthening the public law element in the regulation, and providing for the fundamentals for the payment and formation of such payment for obligatory and necessary services.

Keywords: public services, paid services, free-of-charge services, obligatory services, necessary service, price formation principles, state bodies, commercialization of public government, subsidiary responsibility, executive and administrative competence. 


\section{Финансовое право и управление - №1(3)•2014}

B рамках оптимизации предоставления публичных услуг, повышения их доступности и снижения административных барьеров Правительством РФ взят курс на упорядочение взимания платы при их предоставлении, предполагающий отмену такой платы или ее перевод в государственную пошлину1. Такой подход в полной мере соответствует требованиям Федерального закона «Об организации предоставления государственных и муниципальных услуг» от 27.07.2010 г. № 210-Ф3, п. 1 ст. 8 которого предусматривает по общему правилу оказание соответствующих услуг на бесплатной основе. Исключение составляют случаи взимания с заявителей государственной пошлины (п. 2), а также взимание платы впредь до признания утратившими силу положений нормативноправовых актов, которыми она была установлена (п. 3).

Однако это касается тех услуг, которые оказывают по запросам заявителей непосредственно органы публичной власти и которые связаны с реализацией этими органами в пределах предоставленной им компетенции исполнительно-распорядительных полномочий, в том числе в части предоставления заявителям тех или иных прав или выдачи разрешений. В свою очередь, для принятия в отношении заявителей управленческих решений в тех или иных сферах может возникать потребность в получении данных, установление которых требует специальных познаний и основывается на проведении экспертиз, обследований, испытаний, оценок, проверок соответствия и т.д.

В этих случаях обращение заявителя в государственный или муниципальный орган

\footnotetext{
${ }^{1}$ Распоряжение Правительства РФ «Об утверждении Концепции снижения административных барьеров и повышения доступности государственных и муниципальных услуг на 2011-2013 годы и плана мероприятий по реализации указанной Концепции» от 10.06.2011 г. № 1021-p.
}

предваряется обязательным оказанием ему услуги, необходимой для принятия органом по его заявлению законного и обоснованного решения. Но, несмотря на прямую сопряженность получения необходимых и обязательных услуг с возможностью последующего обращения за реализацией права в государственный или муниципальный орган, требования к взиманию платы за их предоставление сформулированы Федеральным законом от 27.07.2010 г. № 210-Ф3 уже менее жестко. Пункт 2 ст. 9 предусматривает оказание соответствующих услуг за счет средств заявителей в случаях, предусмотренных федеральными законами, принимаемыми в соответствии с ними иными нормативными правовыми актами Российской Федерации, нормативными правовыми актами субъектов РФ, муниципальными правовыми актами.

Симптоматично, что требуя нормативного закрепления исчерпывающих перечней необходимых и обязательных услуг на федеральном уровне, уровне субъектов РФ и муниципальных образований (п. 1 ст. 9), законодатель прямо не ограничивает возможности оказания их на платной для заявителя основе. Такой вывод напрашивается в связи с использованием в законе довольно расплывчатой формулировки, допускающей введение рассматриваемой платы нормативными правовыми актами, как на федеральном уровне, так и на уровне субъектов РФ и муниципальных образований, если только они приняты в соответствии с федеральными законами.

Хотя не исключено оказание таких услуг и на бесплатной для заявителя основе. Так, подавляющая часть услуг, которые признаны в соответствии с Постановлением Правительства РФ от 06.05.2011 г. № 352 необходимыми и обязательными для предоставления государственных услуг федеральными органами исполнительной власти, оказывается за счет средств заявителя. Вместе с тем есть 
и такие, которые оплачиваются заявителем в случаях, предусмотренных нормативными правовыми актами. К их числу отнесено, например, выполнение работ по подтверждению соответствия, проводимых в соответствии с законодательством РФ о техническом регулировании (п. 39 перечня).

Очевидно, что организация предоставления необходимых и обязательных услуг без взимания с заявителей платы возможна лишь в случае финансирования деятельности по их оказанию за счет средств соответствующих бюджетов бюджетной системы РФ. В этих целях Бюджетный кодекс РФ позволяет использовать формы финансирования государственного (муниципального) задания на оказание государственных (муниципальных) услуг, формируемого для бюджетных, автономных, а также казенных учреждений. Кроме того, в силу абз. 4 ст. 69.1 БК РФ возможно субсидирование деятельности некоммерческих организаций, не являющихся государственными (муниципальными) учреждениями, в соответствии с договорами (соглашениями) на оказание этими учреждениями государственных (муниципальных) услуг физическим или юридическим лицам.

Вместе с тем может иметь место формирование собственником для государственного (муниципального) учреждения задания и на оказание физическим или юридическим лицам услуг на платной основе. Абзац 8 ч. 1 ст. 62.2 БК РФ прямо предусматривает включение в содержание государственного (муниципального) задания предельных цен (тарифов) на оплату соответствующих услуг физическими или юридическими лицами в случаях, если законодательством РФ предусмотрено их оказание на платной основе, либо порядок установления указанных цен (тарифов) в случаях, установленных законодательством РФ.

Более того, в условиях действующего правового регулирования формирование таких заданий представляется оптимальной формой организации публичным субъектом предоставления государственными (муниципальными) учреждениями тех необходимых и обязательных услуг, на оказание которых продолжает сохраняться публичная монополия, когда к их предоставлению не допускаются частные юридические лица и индивидуальные предприниматели. В этом случае и в силу признания таких услуг в качестве необходимого условия реализации публичным органом в отношении заявителей исполнительно-распорядительных полномочий должна быть обеспечена доступность этих услуг для заявителей путем должной организации их оказания профильными государственными (муниципальными) учреждениями, что и достигается путем формирования для них соответствующих государственных (муниципальных) заданий ${ }^{1}$.

Не обладая сама по себе признаками властности, деятельность по предоставлению необходимых и обязательных услуг приобретает, тем не менее, для публичного субъекта особую значимость, поскольку создает условия и предпосылки для эффективной реализации органами их полномочий. В свою очередь, для заявителя обязательность обращения за получением такой услуги становится одним из публичных барьеров доступа к реализации своего права, что предопределяет необходимость поиска разумного баланса публичного и частного интересов, в том числе в части регулирования вопросов платности необходимых и обязательных услуг.

Будучи направленной на создание условий для надлежащей реализации органами публич-

\footnotetext{
${ }^{1}$ Исключением является, пожалуй, лишь предоставление таких услуг казенными учреждениями, возложение на которые соответствующих задач может не сопровождаться в силу специфики статуса учреждений данного типа формированием для них государственного (муниципального) задания в соответствии с положениями Бюджетного кодекса РФ.
} 


\section{Финансовое право и управление - №1(3)•2014}

ной власти исполнительно-распорядительных полномочий, деятельность по оказанию необходимых и обязательных услуг не предполагает наделения осуществляющего ее субъекта властными полномочиями, расширяя в связи с этим пределы дискреции законодателя в ее регулировании. Однако она должна быть надлежащим образом организована государством и в силу публичной значимости не может осуществляться в рамках свободного рынка услуг без участия публичного субъекта в определении круга допускаемых к оказанию необходимых и обязательных услуг лиц. В частности, в силу ст. 2 и ч. 1 ст. 26 Федерального закона «О техническом регулировании» от 27.12.2002 г. № 184-Ф3 обязательное подтверждение соответствия объектов требованиям технических регламентов и положениям стандартов осуществляется юридическими лицами или индивидуальными предпринимателями, аккредитованными в порядке, установленном Правительством РФ.

Представляется, что характер необходимой и обязательной услуги не исключает возможность ее предоставления на основании договора, заключаемого в соответствии с гражданским законодательством, и распространения на отношения сторон норм гражданского законодательства, если иное не предусмотрено федеральным законом. Однако сама по себе допустимость использования гражданскоправового инструментария в этом случае не отрицает публичного характера соответствующей деятельности, как позволяющей выявить основания для принятия публичных решений в отношении заявителей, что исключает возможность рассматривать ее в качестве инструмента извлечения прибыли.

Публичный характер необходимой и обязательной для реализации полномочий государственных (муниципальных) органов услуги не может, таким образом, не влиять на природу взимаемой за ее оказание платы, размер которой, во всяком случае, не может предопределяться действием обычных рыночных инструментов и требует публичного регулирования. При этом с конституционных позиций в целях повышения доступности соответствующих услуг должно быть обеспечено по возможности приближение размера этой платы к уровню экономически обоснованных затрат, обусловленных их предоставлением, если публичный субъект на данном этапе экономического развития не может организовать оказание таких услуг на бесплатной для заявителя основе.

Более того, плата за необходимые и обязательные услуги, оказываемые государственными (муниципальными) учреждениями в условиях отсутствия доступа к их предоставлению у негосударственных юридических лиц и индивидуальных предпринимателей, не может преследовать цель извлечения учреждением доходов как хозяйствующим субъектом. В этом случае с конституционных позиций взимание платы допустимо, на наш взгляд, исключительно в качестве компенсации затрат на осуществление публичной функции. Иной подход создавал бы угрозу необоснованной коммерциализации государственной (муниципальной) деятельности и нарушения свободной конкуренции хозяйствующих субъектов, поскольку обеспечивал бы государственным (муниципальным) структурам монопольные условия для извлечения дохода в рамках осуществления публичных функций.

Именно поэтому за государственными (муниципальными) учреждениями, содержание которых осуществляется публичным субъектом на основе сметного финансирования, в условиях оказания ими монополизированных публичным субъектом необходимых и обязательных услуг не может быть признано право на полученный от их оказания доход. Это значит, что в данном случае при возложении на такие учреждения задач по оказанию 
необходимых и обязательных услуг, плата за эти услуги с конституционных позиций может взиматься лишь при условии изьятия ее в бюджет. Такое изъятие в условиях действующего правового регулирования с учетом выраженных Конституционным Судом РФ правовых позиций представляется возможным либо в качестве государственной пошлины, либо в качестве компенсации затрат публичного субъекта, приобретающей в этом случае признаки фискального сбора.

Изложенный подход позволяет исключить необоснованную коммерциализацию публичной власти за счет создания монопольных условий для хозяйственной деятельности учреждений как некоммерческих организаций, финансовое обеспечение выполнение функций которых должно осуществляться, прежде всего, за счет средств соответствующих бюджетов. Вместе с тем ситуация меняется в связи с реформированием статуса государственных (муниципальных) учреждений и преобразованием их в бюджетные учреждения нового типа, а также автономные учреждения. Как известно, особенности правового положения таких учреждений определяются отказом от содержания их собственником на основании сметы, равно как и от субсидиарной ответственности по их долгам.

Признание известной автономии реформированных учреждений как самостоятельных экономических институциональных единиц в условиях провозглашаемого ослабления административного управления ими со стороны учредителя дает основания для постановки вопроса о поступлении в этих условиях платы за оказание ими необходимых и обязательных услуг в их распоряжение. Однако учитывая, что создание этих учреждений как некоммерческих организаций осуществляется, тем не менее, в целях обеспечения исполнения полномочий органов публичной власти, в условиях сохранения государственной монополии на оказание необходимых услуг, размер платы, поступающий учреждениям от их оказания, во всяком случае, не может превышать реального уровня затрат, обусловленного их предоставлением.

К сожалению, действующее законодательство, как представляется, не содержит должной определенности в регулировании соответствующих вопросов и пока не в полной мере отвечает в этой части уровню конституционных требований. Прежде всего, вызывает вопросы положение п. 9 ст. 15 Федерального закона «О защите конкуренции» от 26.07.2006 г. № 135-Ф3. В соответствии с ним (в редакции Федерального закона от 26.12.2011 г.) запрещается как ограничивающее конкуренцию установление и (или) взимание не предусмотренных законодательством РФ платежей при предоставлении государственных или муниципальных услуг, а также услуг, которые являются необходимыми и обязательными для их предоставления.

Буквальное прочтение приведенной нормы позволяет сделать вывод о том, что законодатель усматривает подлежащее запрету нарушение конкуренции только в том случае, если устанавливаются и (или) взимаются платежи, не предусмотренные законодательством РФ. При этом отсутствуют оговорки относительно допустимых пределов производимых при предоставлении необходимых и обязательных услуг изъятий в случае их монопольного предоставления государственными (муниципальными) структурами. Федеральный закон «Об организации предоставления государственных и муниципальных услуг» от 27.07.2010 г. № 210-Ф3 также не содержит каких-либо ограничений на этот счет. Закрепляя требования к взиманию с заявителя платы за такие услуги, п. 3 ст. 9 определяет, что ее размер устанавливается на федеральном уровне - в порядке, установленном Правительством РФ, а на региональном и местом уровне - нормативным 


\section{Финансовое право и управление - №1(3)•2014}

правовым актом соответственно высшего исполнительного органа государственной власти субъекта РФ, представительного органа местного самоуправления.

Так, Правила определения размера платы за оказание услуг, которые являются необходимыми и обязательными для предоставления федеральными органами исполнительной власти государственных услуг утверждены Постановлением Правительства РФ от 06.05.2011 г. № 352¹. В силу п. 5 правил размер платы за оказание услуг, предоставляемых федеральными учреждениями и унитарными предприятиями, определяется в соответствии с порядком, устанавливаемым федеральным органом исполнительной власти, осуществляющим функции и полномочия их учредителя, на основании методики. В свою очередь, если иное не установлено постановлениями Правительства РФ, методика определения размера платы, а также его пределы утверждаются федеральными министерствами (а в отношении услуг, предоставляемых учреждениями и предприятиями, находящимися в ведении федеральных служб и агентств, руководство которыми осуществляют Президент РФ или Правительство РФ - соответствующими службами и агентствами) (п. 2). При этом проект нормативного правового акта федерального органа исполнительной власти об утверждении методики и предельных размеров платы подлежит согласованию с Федеральной антимонопольной службой (п. 4).

Анализ утверждаемых федеральными органами исполнительной власти методик показывает, что они исходят из определения размера платы за необходимую и обязательную услугу

\footnotetext{
1 Аналогичные правила определения размера платы за оказание услуг, которые являются необходимыми и обязательными для предоставления государственных услуг исполнительными органами государственной власти Санкт-Петербурга утверждены Постановлением Правительства Санкт-Петербурга от 03.02.2012 г. № 93.
}

на уровне экономически обоснованных затрат, связанных с ее оказанием. Соответственно размер платы определяется как сумма прямых и накладных расчетно-нормативных расходов в зависимости от трудоемкости конкретной услуги ${ }^{2}$. Тем не менее следует обратить внимание на отсутствие на уровне федерального закона положений, определяющих принципы формирования платы за необходимые и обязательные услуги, которые обеспечивали бы ее изъятие на конституционно допустимом уровне, что потенциально затрудняет возможность защиты прав потребителей таких услуг в случае необоснованного завышения установленной на нее цены (тарифа).

В связи с этим представляется необходимым выведение соответствующих гарантий на законодательный уровень, тем более в условиях сохранения государственной монополии на предоставление значительной части необходимых и обязательных услуг, поскольку это позволит одновременно создать также необходимые предпосылки для того, чтобы избежать коммерциализации публичной деятельности и нарушения требований защиты конкуренции.

Проблемы правового регулирования платы за предоставление необходимых и обя-

\footnotetext{
${ }^{2}$ См., например: приказ Минприроды РФ «Об утверждении методики расчета платы за государственную экологическую экспертизу» от 08.07.2010 г. № 251; приказ Минсельхоза России «Об утверждении методик определения размеров платы за оказание необходимых и обязательных услуг, предоставляемых федеральными государственными бюджетными учреждениями и федеральными государственными унитарными предприятиями, находящимися в ведении Федеральной службы по ветеринарному и фитосанитарному надзору» от 22.03.2012 г. № 194; приказ Минздравсоцразвития РФ «Об утверждении методики определения размера платы за оказание необходимой и обязательной услуги по медицинскому освидетельствованию с выдачей справки в целях предоставления государственных услуг федеральными органами исполнительной власти и предельных размеров на ее оказание» от 17.02.2012 г. № 139н.
} 
зательных услуг усматриваются и в том случае, когда к их предоставлению допускаются в установленном порядке негосударственные организации и индивидуальные предприниматели. Например, в соответствии со ст. 43 Федерального закона от 30.03.1999 г. № 52-Ф3 «О санитарно-эпидемиологическом благополучии населения» аккредитованные организации в целях государственной регистрации веществ и продукции осуществляют оценку опасности веществ и отдельных видов продукции для человека и среды обитания, установление гигиенических и иных нормативов содержания веществ и отдельных компонентов в среде обитания.

Однако, несмотря на допуск в установленном порядке к оказанию необходимых и обязательных услуг частных лиц законодатель, тем не менее, оставляет открытым вопрос о порядке формирования платы за их предоставление. Положения ст. 9 Федерального закона «Об организации предоставления государственных муниципальных услуг» от 27.07.2010 г. № 210Ф3 формально могли бы рассматриваться в качестве устанавливающих универсальные требования к взиманию с заявителя платы независимо от субъекта, оказывающего такую услугу. Закон не содержит оговорок относительно применения содержащихся в нем указаний относительно порядка определения размера платы только в случае оказания таких услуг государственными (муниципальными) учреждениями (предприятиями).

Вместе с тем принятые в соответствии с требованиями закона Правительством РФ Правила определения размера платы за оказание услуг, которые являются необходимыми и обязательными для предоставления федеральными органами исполнительной власти государственных услуг устанавливают порядок формирования платы только за услуги, оказываемые федеральными государственными учреждениями и федераль- ными унитарными предприятиями. В связи с этим следует напомнить, что первоначально Постановление Правительства РФ «О перечне платных услуг, оказываемых организациями в целях предоставления федеральными органами государственных услуг» от 02.12.2009 г. № 984 в п. 2 вообще содержало прямой запрет на оказание соответствующих услуг иными организациями, кроме федеральных государственных учреждений и федеральных унитарных предприятий.

Такой подход со всей очевидностью вступал в ряде случаев в противоречие с положениями федеральных законов, прямо предусматривающих допуск к оказанию необходимых и обязательных услуг аккредитованных в установленном порядке частных субъектов, что привело к оспариванию законности абз. 2 п. 2 Постановления Правительства РФ от 02.12.2009 г. № 984 в Верховном Суде РФ. Прошедшее соответствующую аккредитацию частное учреждение ссылалось на необоснованное сужение оспариваемым постановлением круга лиц, имеющих право на проведение санитарно-эпидемиологических экспертиз для целей государственной регистрации, усматривая в этом противоречие Федеральному закону «О санитарно-эпидемиологическом благополучии населения» от 30.03.1999 г. № 52-Ф3. Согласившись с доводами заявителя, Верховный Суд РФ Решением от 28.12.2010 г. № ГКПИ10-1298 признал абз. 2 п. 2 Постановления Правительства РФ от 02.12.2009 г. № 984 недействующим в части, исключающей возможность для организаций, не относящихся к федеральным органам исполнительной власти, федеральным государственным учреждениям и федеральным унитарным предприятиям, оказывать платные услуги по проведению санитарно-эпидемиологической экспертизы, расследований, обследований, исследований, испытаний, токсикологических, гигиенических и других видов оценок. 


\section{Финансовое право и управление - №1(3) 2014}

Вновь принятое Постановление Правительства РФ «Об утверждении перечня услуг, которые являются необходимыми и обязательными для предоставления федеральными органами исполнительной власти государственных услуг и предоставляются организациями, участвующими в предоставлении государственных услуг, и определении размера платы за их оказание» от 06.05.2011 г. № 352 запрета на оказание соответствующих услуг иными организациями, кроме федеральных государственных учреждений и федеральных унитарных предприятий, более не содержит. Вместе с тем правила формирования платы за такие услуги по-прежнему установлены лишь для государственных организаций, причем в соответствии с требованиями Федерального закона от 27.07.2010 г. № 210-Ф3 - на подзаконном уровне.

Симптоматично, что федеральное законодательство не только не содержит универсальных принципов формирования платы за оказание необходимых и обязательных услуг, но и позволяет в некоторых случаях усматривать допустимость ее весьма широких возможных пределов. Так, п. 4 ст. 23 Федерального закона «О техническом регулировании» от 27.12.2007 г. № 184-ФЗ содержит положение, в соответствии с которым стоимость работ по обязательному подтверждению соответствия продукции определяется на основании договора с заявителем независимо от страны и (или) места ее происхождения, а также лиц, которые являются заявителями. Ограничиваясь приведенными требованиями, законодатель тем самым не исключает возможности свободного определения соответствующей платы на основании заключаемого с заявителями договора, если только при этом отсутствует дифференциация платы по дискриминирующим основаниям и не нарушается конституционный принцип формального равенства.
Наличие при этом специальных правил формирования платы за необходимые и обязательные услуги, оказываемые государственными учреждениями и унитарными предприятиями, формально приводит к возможности возникновения ситуации оказания необходимых и обязательных услуг аккредитованными негосударственными организациями и индивидуальными предпринимателями за плату, более высокую по своим размерам в сравнении с платой, применяемой государственными организациями. Однако допустимость такого подхода вызывает известные сомнения, в том числе с позиций проводимой в настоящее время реформы статуса государственных (муниципальных) учреждений, нацеленной на обеспечение в значительной мере их экономической самостоятельности и предполагающей в связи с этим отказ собственника от содержания бюджетных учреждений нового типа и автономных учреждений на основе сметы.

Финансовое обеспечение формируемых для таких учреждений государственных (муниципальных) заданий в форме предоставления субсидий на возмещение нормативных затрат на оказание государственных (муниципальных) услуг с одновременным предоставлением возможности самостоятельного распоряжения получаемыми доходами призваны создать условия для их эффективного функционирования в условиях конкурентной среды и обеспечить повышение качества публичных услуг. На то, что конкуренция учреждений с негосударственными организациями способствует ориентации бюджетных расходов не на содержание сети учреждений, а на обеспечение результативности их деятельности обращалось внимание в Бюджетном послании Президента РФ Федеральному Собранию от 29.06.2011 г. «О бюджетной политике в 2012-2014 годах».

Представляется, что в условиях качественно новых взаимоотношений реформированных 
учреждений с публичным субъектом, сопряженных с отказом от субсидиарной ответственности по их долгам, появляются основания для постановки вопроса об обеспечении в определенных пределах сопоставимости параметров оказания ими публичных услуг в сравнении с негосударственными организациями. В том числе это касается и принципов формирования платы за услуги, необходимые и обязательные для предоставления тех услуг, которые оказывают по запросам заявителей органы публичной власти и которые связаны с реализацией этими органами в пределах предоставленной им компетенции исполнительно-распорядительных полномочий.

Таким образом, обращение к вопросам правового регулирования платы за оказание услуг, которые являются необходимыми и обязательными для предоставления государственных и муниципальных услуг, даже в первом приближении обнаруживает ряд проблем, вызванных особенностями природы таких услуг и заслуживающих, как представляется, большего внимания со стороны федерального законодателя. В этом отношении представляется необходимым усиление публично-правовой составляющей регулирования, в рамках которого, в том числе, могли бы быть определены правовые основы организации предоставления необходимых и обязательных услуг и формирования платы за такие услуги, гарантирующие ее изъятие на конституционно допустимом уровне при обеспечении надлежащего качества услуг. 